\title{
Technical note \\ Development of a Linear Flow Channel Reactor for sulphur removal in acid mine wastewater treatment operations
}

\author{
JB Molwantwa' and PD Rose ${ }^{2 *}$ \\ 'Digby Wells Environmental, Private Bag X10046, Randburg 2125, Johannesburg, South Africa \\ ${ }^{2}$ Department of Biochemistry, Microbiology and Biotechnology, Rhodes University, Grahamstown, 6140, South Africa
}

\begin{abstract}
Where sulphate removal is targeted in the biological treatment of acid mine drainage wastewaters, a step additional to sulphate reduction is required to prevent the complete oxidation of sulphide back to sulphate. This linearisation of the biological sulphur cycle has presented a technological bottleneck, particularly in passive treatment operations. We report an investigation of sulphur production in floating sulphur biofilms as a means for addressing this problem. These $50 \mu \mathrm{m}$ to $500 \mu \mathrm{m}$ structures may be seen to form on the surface of sulphidic, organic waters and in which sulphide is partly oxidised to $S_{\circ}$ and polysulphide. A Linear Flow Channel Reactor was developed in which the formation of the floating sulphur biofilm could be optimised and studied under controlled conditions. In this study the sulphide feed was sourced from a lignocellulose packed bed reactor treating a synthetic acid mine water $\left(2000 \mathrm{mg} \cdot \ell^{-1} \mathrm{Na}_{2} \mathrm{SO}_{4}\right.$ solution) and the Liner Flow Channel Reactors (surface area $1.1 \mathrm{~m}^{2}$ and $2.2 \mathrm{~m}^{2}$ ) were operated in a controlled environment chamber. The floating sulphur biofilm was harvested by settling to the bottom of the reactor where it remained largely unreacted until removed. It was shown that up to $88 \%$ of sulphide in the feed stream may be removed in this way and that this was achieved mainly by oxidation of sulphide to sulphur (including a polysulphide fraction). A mass balance accounting for the process showed that up to $66 \%$ of total sulphur species entering the system were recovered as $\mathrm{S}_{\mathrm{o}}$. Oxidation of sulphide to thiosulphate and sulphate was not found to be significant. A fraction of fine particulate sulphur is released into the stream on harvesting of the biofilm which does not readily settle in the reactor and may thus be lost to the mass balance account. The effects of temperature, loading rate and reactor surface area were investigated in optimising the performance of the reactor. Scale-up application studies in the use of the Linear Flow Channel Reactor in an acid mine drainage passive treatment environment have been undertaken in field studies.
\end{abstract}

Keywords: floating sulphur biofilms, acid mine drainage, AMD passive treatment, linear flow channel reactor, sulphur biotechnology

\section{INTRODUCTION}

Environmental impacts of acid mine drainage (AMD) on public water systems may be widespread and South Africa presents a paradigm case where, following over a century of intensive gold and coal mining operations, water-scarce Witwatersrand and Mpumalanga areas are now under threat (McCarthy, 2011). Both large-volume and diffuse flows require treatment and biological processes offer potential advantages of low cost and low operational input requirements, particularly where applied in passive treatment operations (Molwantwa et al., 2009). The long-term nature of the problem also needs to be considered and, with certain Roman mine workings in Britain and Europe reportedly still actively generating AMD some 2000 years later (Field, 2003), the extended time frames over which the problem will require treatment needs to be taken into account. The sustainability of treatment operations over the long time periods anticipated also favours biological process options (Rose, 2005).

Biological treatment involves the manipulation of the biological sulphur cycle at one or more of its stages of operation, with the reduction of sulphate to sulphide by sulphate-reducing prokaryote (SRP) populations and providing the first unit operation in the process. Apart from neutralisation and metal

To whom all correspondence should be addressed.

+2782 801-1353; e-mail: p.rose@ru.ac.za

Received 30 July 2012; accepted in revised form 23 September 2013. removal functions, which may be effected at this stage, it is also necessary to remove sulphur from the stream in one of its reduced forms in order to prevent its complete oxidation back to sulphate. However, linearisation of the biological sulphur cycle has presented a technology bottleneck, particularly in the development of passive treatment operations, and a variety of processes have been considered for the effective removal of sulphur (Molwantwa et al., 2009).

Here we report a bioprocess development study on sulphur removal from AMD which is based on its formation in floating sulphur biofilms (FSB). These structures, which are $50 \mu \mathrm{m}$ to $500 \mu \mathrm{m}$ thick, form on the surface of sulphidic, organic waters (Fig. 1A), and our initial observation and investigation of FSB structures were reported for tannery wastewater evaporation ponds (Rose et al., 1996; Dunn, 1998). FSB have been shown to be true biofilms in both structural and functional features (Gilfillan 2000; Rein 2002; Bowker, 2002; Rose et al., 2002; Molwantwa et al., 2007). Molwantwa (2008) demonstrated the presence of well-differentiated aerobic, anoxic and anaerobic functional zones within these biofilms in which redox conditions are poised over a narrow range around $-150 \mathrm{mV}$ and thereby enable sulphur formation in the polysulphide and orthorhombic $S_{\text {o }}$ forms (Fig. 2). Where conditions are maintained that allow the biofilm to thicken, it will finally break away from the surface and settle at the bottom of a reactor vessel, where it remains largely unreacted until removed.

Preliminary studies on the use of the FSB system for sulphur removal in Integrated Managed Passive Treatment 

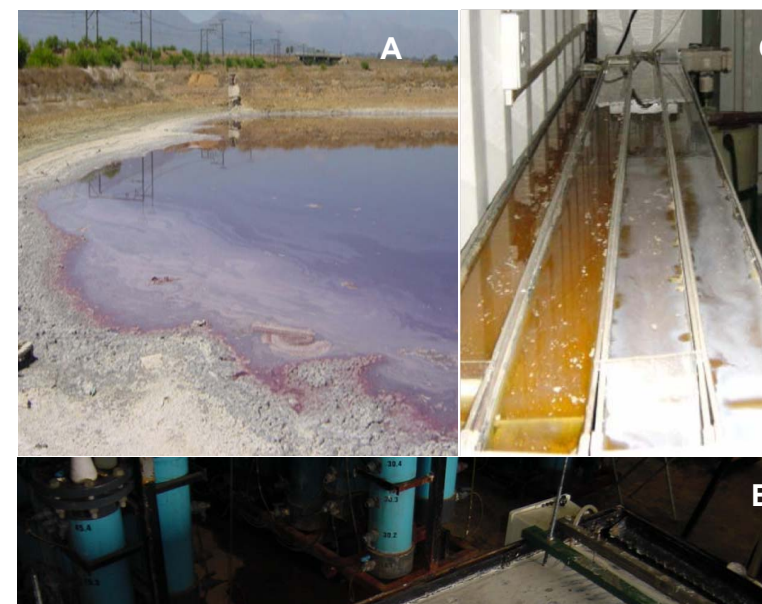

B

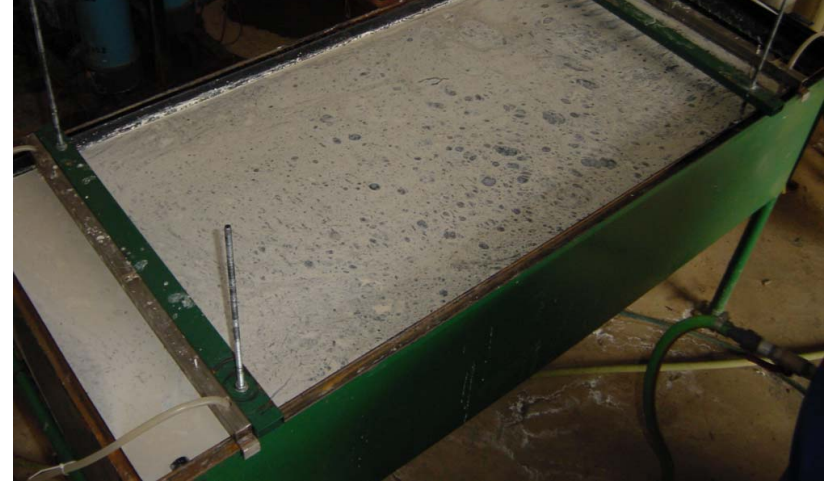

Figure 1

A. Floating sulphur biofilms formed on the surface of a tannery wastewater evaporation pond operated in Wellington, South Africa. B. Floating sulphur biofilm formation in a field-scale experimental reactor which received sulphide feed from a degrading packed bed reactor which in turn was fed with an acid mine drainage wastewater. C. Photograph showing the Linear Flow Channel Reactor experimental setup as operated in a controlled environment chamber.

Systems (IMPI) had demonstrated a potentially robust application for the process under field conditions (Molwantwa et al., 2007). Here it had been located as a unit operation following AMD sulphate reduction in the lignocellulose-based Degrading Packed Bed Reactor (DPBR) described by Coetser et al. (2005). However, under these conditions it had proved difficult to derive operational and kinetic data for purposes of process design and systematic scale-up from the field-scale floating biofilm reactor system first used (Fig. 1B).

Here we report the development of the Liner Flow Channel Reactor (LFCR) in which FSB formation and sulphur removal could be studied under controlled experimental conditions. Process variables investigated included reactor surface area, loading rate of the sulphide stream and the effect of temperature on process operation.

\section{MATERIALS AND METHODS}

Shallow rectangular PVC channels $(100 \mathrm{~mm}$ deep and $150 \mathrm{~mm}$ wide) were used for the construction of the reactor vessels (Fig. 1C). These were connected in series in configurations of 4 and also 8 channel units, providing a total surface area of $1.1 \mathrm{~m}^{2}$ and $2.2 \mathrm{~m}^{2}$, respectively. Surface baffles were fitted at the outlet of each channel section and thus constraining the floating film within the channel reactor.

A synthetic mine-water $\left(2000 \mathrm{mg} \cdot \ell^{-1} \mathrm{Na}_{2} \mathrm{SO}_{4}\right)$ was prepared using industrial grade sodium sulphate (Protea Chemicals), and then fed to a molasses supplemented $10 \mathrm{~m}^{3} \mathrm{DBPR}$ which is a lignocellulose-packed unit developed for AMD passive treatment operations and in which the sulphate reduction reaction is optimised (Coetser et al., 2005).

The LFCR was operated in a controlled environment chamber with operational temperatures set at $15^{\circ} \mathrm{C}\left( \pm 0.5^{\circ} \mathrm{C}\right) ; 20^{\circ} \mathrm{C}$ $\left( \pm 0.5^{\circ} \mathrm{C}\right)$ and $25^{\circ} \mathrm{C}\left( \pm 0.5^{\circ} \mathrm{C}\right)$ for each of the temperatures studied. The DPBR sulphide feed stream to the LFCR was fed at loading rates of $1309 \mathrm{l} \cdot \mathrm{m}^{-2} \cdot \mathrm{day}^{-1}$ and $2618 \mathrm{l} \cdot \mathrm{m}^{-2} \cdot \mathrm{day}^{-1}$.

\section{Operation}

Operating variables were examined in the LFCR in a series of runs in which the effects on the process of temperature, feed loading rate and reactor surface area were measured. Before each run the reactor was drained and cleaned and then a run commenced with filling of the reactor with sulphide feed from the DPBR. After a period of 24 to $48 \mathrm{~h}$ the FSB would establish on the water surface in the reactor and develop through 3 clearlydefined stages of 'thin', 'sticky' and 'brittle' biofilm, as described by Molwantwa (2008). The appearance of polysulphide/S granules in the biofilm has been linked to the appearance of 'brittle' texture biofilm. Once the 'brittle' film had appeared, loading at the desired rate commenced and, in particular, loading rates of $1309 \mathrm{l} \cdot \mathrm{m}^{-2} \cdot \mathrm{day}^{-1}$ and $2618 \mathrm{l} \cdot \mathrm{m}^{-2} \cdot \mathrm{day}^{-1}$ were evaluated. Harvesting of the FSB involved spraying a fine mist of tap water onto the surface of the 'brittle' film which resulted in portions becoming destabilised, breaking away and then settling to the bottom of the reactor channel. This allowed the formation of new 'thin' and 'sticky' film at the surface and, when full coverage with 'brittle' film was complete, the harvesting process was repeated once again. Harvesting was thus undertaken every 12 to $18 \mathrm{~h}$ over the time period of the particular run.

Daily analyses of the influent and effluent flows were undertaken for soluble sulphide, sulphate, thiosulphate and sulphur for purposes of mass balance determination. Once a run had been completed the reactor was drained, the sulphur biofilm material which had settled in the reactor channels was collected, dried and weighed, and analysed for sulphur content. A cone settler was located at the LFCR outflow to collect smaller particles that may be carried along with the stream flow. This was also emptied and the sulphur biofilm material collected, dried and added to that recovered from the LFCR. The volume of liquid drained from the reactor and cone settler was also measured and the final analyses used for mass balance determinations as outlined below.

\section{Analysis}

Triplicate samples were drawn for each of the data sets reported and analysed for soluble sulphide, sulphate, thiosulphate, sulphur and $\mathrm{pH}$, Redox potential and COD. Results were averaged and reported as the mean of 3 samples.

\section{Sulphide}

The Merck Spectroquant system was used for soluble sulphide determination (Merck, South Africa). Samples were collected in test tubes containing $100 \mu \ell$ of $0.1 \mathrm{M}$ zinc acetate solution. Photometric readings were made using the SQ 118 spectrophotometer (Merck, South Africa).

\section{Sulphate and thiosulphate}

Sulphate was determined using ion chromatography in a Waters model 600 HPLC and Waters model 432 conductivity 

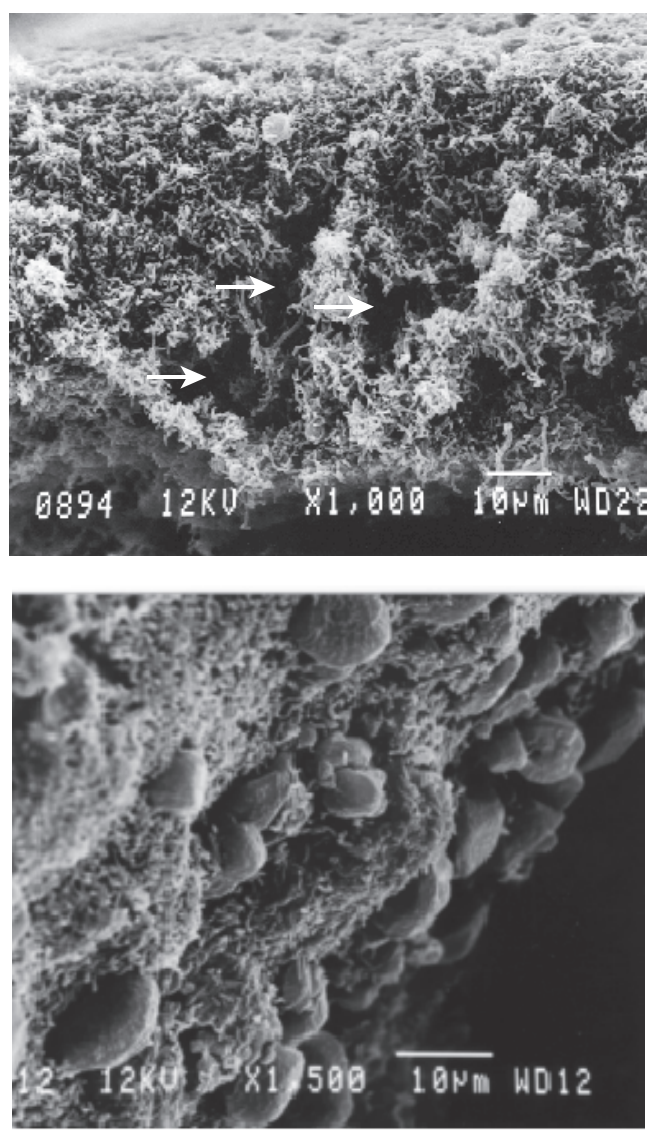

Figure 2

Electron micrographs of floating surphur biofilm in cross section showing the porous nature of the biofilm (white arrows indicating spaces within the biofilm) and also the formation of granular sulphur structures on the underside of the biofilm (Molwantwa 2008).

detector (Waters, South Africa) fitted with an IC-Pak ${ }^{\mathrm{TM}}$ anion 4.6 x $50 \mathrm{~mm}$ column (Waters, South Africa). Samples were prepared using a 10 -fold dilution of sample in milliQ water and then filtered through a $0.45 \mu \mathrm{m}$ nylon filter before being passed through 2 Waters Sep-Pak light $\mathrm{C}_{18}$ cartridges (Waters, South Africa) to remove contaminating organic compounds. The system was run at a flow rate of $1 \mathrm{~m} \ell \cdot \mathrm{min}^{-1}$ and results analysed using the EMPOWER software programme (Waters, South Africa). A borate/gluconate buffer was used for eluent preparation. All chemicals and filters were from Merck, South Africa. A standard solution containing $\mathrm{Fe}, \mathrm{Cl}^{-}, \mathrm{NO}_{3}^{-}, \mathrm{Br}^{-}, \mathrm{HPO}_{4}{ }^{2-}$ and $\mathrm{SO}_{4}{ }^{2-}$ in milliQ water was prepared weekly.

\section{Sulphur}

A reverse-phase HPLC method was used for sulphur determination (modified from Mockel 1984). Three $1 \mathrm{ml}$ samples were collected, centrifuged for $5 \mathrm{~min}$ at $13000 \mathrm{r} \cdot \mathrm{min}^{-1}$ on an Eppendorf 5415D centrifuge and air dried. After drying, $1 \mathrm{~m} \ell$ acetone was added to the pellet and left to stand for $1 \mathrm{~h}$ with vigorous shaking every $10 \mathrm{~min}$. The samples were filtered through a $0.45 \mu \mathrm{m}$ nylon filter (Merck, South Africa) and analysed using the EMPOWER software on a Waters 600 model HPLC and a Waters model 2487 dual $\lambda$ absorbance detector fitted with a Nova-Pak $\mathrm{C}_{18} 3.9 \times 150 \mathrm{~mm}$ column (Waters, South Africa). The samples were injected and run at $2 \mathrm{~m} \ell \cdot \mathrm{min}^{-1}$ using a 5:95 ratio of water:methanol (Merck, South Africa) as the

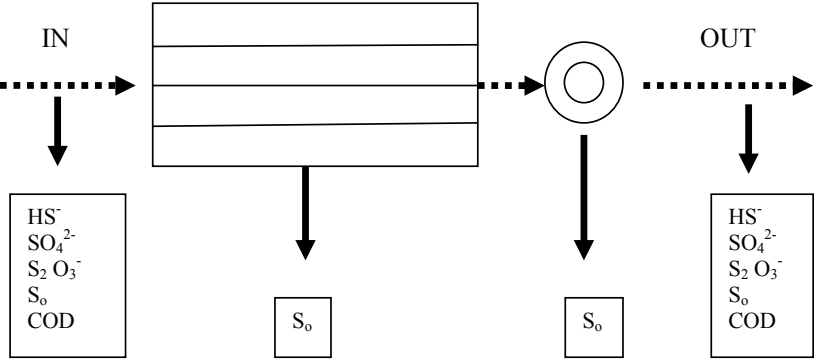

Figure 3

Flow path of the Linear Flow Channel Reactor experimental set up showing sulphide Fiched AMD liquid flow (serrated line) from the Degrading Packed Bed Reactor through the channel reactor and settling cone. Analyses undertaken in the feed and effluent treams are shown in boxes and total sulphur generated was recovered and measured at the end of each run.

eluent. A $20 \mathrm{mg} \cdot \ell^{-1}$ standard solution of elemental sulphur in acetone was used for standardisation.

\section{pH}

$\mathrm{pH}$ was measured using a model $330 \mathrm{WTW} \mathrm{pH} / \mathrm{mV}$ meter (Merck, South Africa).

\section{Redox potential}

Redox potential was measured using a WTW $\mathrm{pH} / \mathrm{mV} 330$ meter (Merck', South Africa).

\section{Chemical oxygen demand}

Chemical oxygen demand (COD) was determined using the digestion and titration method (APHA, 2005).

\section{Floating sulphur biofilm}

After each reactor run settled FSB material was collected and dried at $80^{\circ} \mathrm{C}$ for 5 days.

\section{Mass balance}

Mass balances were calculated to provide an account for influent, effluent and recovered sulphur species calculated as $S$, as shown in the process train (Fig. 3). follows:

The percentage mass balance recovery was calculated as

Total sulphur species IN = Total sulphur species OUT + Total sulphur recovered

$\left(\mathrm{S}^{\circ}+\mathrm{SO}_{4}{ }^{2-}+\mathrm{HS}^{-}+\mathrm{S}_{2} \mathrm{O}_{3}{ }^{-}\right)_{\mathrm{IN}}=\left(\mathrm{S}^{\circ}+\mathrm{SO}_{4}{ }^{2-}+\mathrm{HS}^{-}+\mathrm{S}_{2} \mathrm{O}_{3}{ }^{-}\right)$out

$+\left(\mathrm{S}^{\circ}+\mathrm{SO}_{4}{ }^{2-}+\mathrm{HS}^{-}+\mathrm{S}_{2} \mathrm{O}_{3}\right)^{-}{ }_{\text {RECOVERED }}$

Mass balance loss $(\%)=\left[\left(\mathrm{S}_{\text {IN }}-\mathrm{S}_{\text {OUT }}\right)+\left(\mathrm{S}_{\text {RECOVERED }}\right) /\right.$ $\left.\mathrm{S}_{\mathrm{IN}}\right]^{\star} 100$

Mass balance recovery $(\%)=100-$ Mass balance loss $(\%)$

Sulphide removal $(\%)=\left[\left(\right.\right.$ Sulphide $_{\mathrm{IN}}-$ Sulphide $\left._{\text {OUT }}\right) /$ Sulphide $_{\text {IN }}{ }^{\star} 100$

Sulphur recovery $(\%)=\left[\left(\right.\right.$ Sulphur $_{\text {out }}-$ Sulphur $\left._{\text {IN }}\right) /$ Sulphide ${ }_{\text {IN }}{ }^{\star} 100$ 


\begin{tabular}{|c|c|c|c|}
\hline \multicolumn{4}{|c|}{$\begin{array}{c}\text { TABLE } 1 \\
\text { Effect of temperature on sulphide removal in the } \\
\text { 4-channel reactor at a feed loading rate of } 1309 \\
\ell \cdot \mathrm{m}^{-2} \cdot \mathrm{day}^{-1}\end{array}$} \\
\hline $\begin{array}{c}\text { Temperature } \\
\left({ }^{\circ} \mathrm{C}\right)\end{array}$ & $\begin{array}{c}\text { Mass } \\
\text { balance } \\
\%\end{array}$ & $\begin{array}{c}\text { Sulphide } \\
\text { removal } \\
\%\end{array}$ & $\begin{array}{c}\text { Sulphur } \\
\text { recovery } \\
\%\end{array}$ \\
\hline 25 & 93 & 39 & 36 \\
\hline 20 & 84 & 74 & 43 \\
\hline 15 & 89 & 53 & 28 \\
\hline
\end{tabular}

\section{Statistics}

Statistical evaluation of data sets was undertaken using Statistica data analysis software Version 7.1 (StatSoft, Inc.).

\section{RESULTS AND DISCUSSION}

\section{Temperature}

The effect of temperature on process performance was evaluated at $15^{\circ} \mathrm{C}, 20^{\circ} \mathrm{C}$ and $25^{\circ} \mathrm{C}$. In each case, operation of the experimental 4-channel LFCR $\left(1.1 \mathrm{~m}^{2}\right)$ was repeated over a number of 18-day runs and then 8-day runs from which the data reported here were collected. A loading rate of $1309 \mathrm{l} \cdot \mathrm{m}^{-2}$.day ${ }^{-1}$ of sulphide-enriched synthetic AMD from the DPBR was applied to the LFCR in these runs.

A mass balance for each run was determined (as described above) in order to account for the passage of all sulphur species (as S) passing through the system. Results are reported in Table 1.

Of total sulphide fed to the LFCR, $74 \%$ was removed with the operation at $20^{\circ} \mathrm{C}$. Sulphide removal was reduced at both the lower and the higher operating temperatures with removal of $53 \%$ at $15^{\circ} \mathrm{C}$ and $39 \%$ at $25^{\circ} \mathrm{C}$. The recovery of elemental sulphur $\mathrm{S}_{0}$ (including polysulphide) ranged between $28 \%$ and $43 \%$ of total sulphur species fed to the reactor during the temperature runs (Table 1). Figure 4 shows no significant increase in thiosulphate or sulphate concentration in the effluent over the influent stream ( $p=0.48$ and $p=0.36$ for thiosulphate and sulphate, respectively), which indicates that the unaccounted fraction of sulphur was not primarily due to the near-complete or complete oxidation of influent sulphide. The $\mathrm{pH}$ in the reactor rose to between pH 8 and 8.4 (Fig. 5) which suggests limited losses due to sulphide stripping into the air, except possibly in the influent before $\mathrm{pH}$ elevation. A component of fine particulate sulphur may be released from the FSB during harvesting when the 'brittle' film breaks up and settles to the bottom of the reactor. This fine particulate fraction does not settle readily in either the channels or in the cone settler and may account, in some part, for the discrepancy between sulphide removal and the total sulphur mass balance account.

The results in Fig. 5 were typical for all runs and, in addition to $\mathrm{pH}$, show redox and COD profiles during runs. An elevation in redox potential from around $-230 \mathrm{mV}$ in the influent to $-155 \mathrm{mV}$ in the effluent is important given that the oxidation of sulphide to elemental sulphur, rather than to more oxidised states, occurs in a narrow redox window around $-150 \mathrm{mV}$ (Steudel, 1996). The influent COD was reduced by
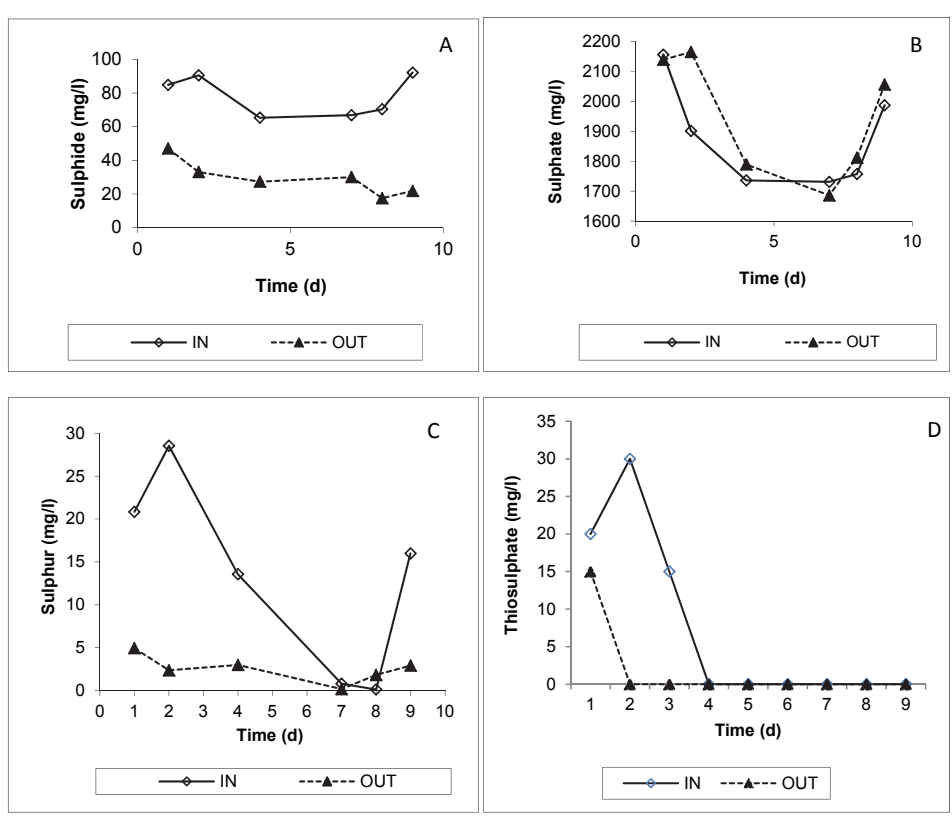

Figure 4

Influent and effluent sulphur species measured in the four-channel Linear Flow Channel Reactor over 8 days at $20^{\circ} \mathrm{C}$ and a $1309 \mathrm{l} / \mathrm{m}^{2} / d$ loading rate. Sulphide (A), sulphate (B), sulphur (C) and thiosulphate (D).
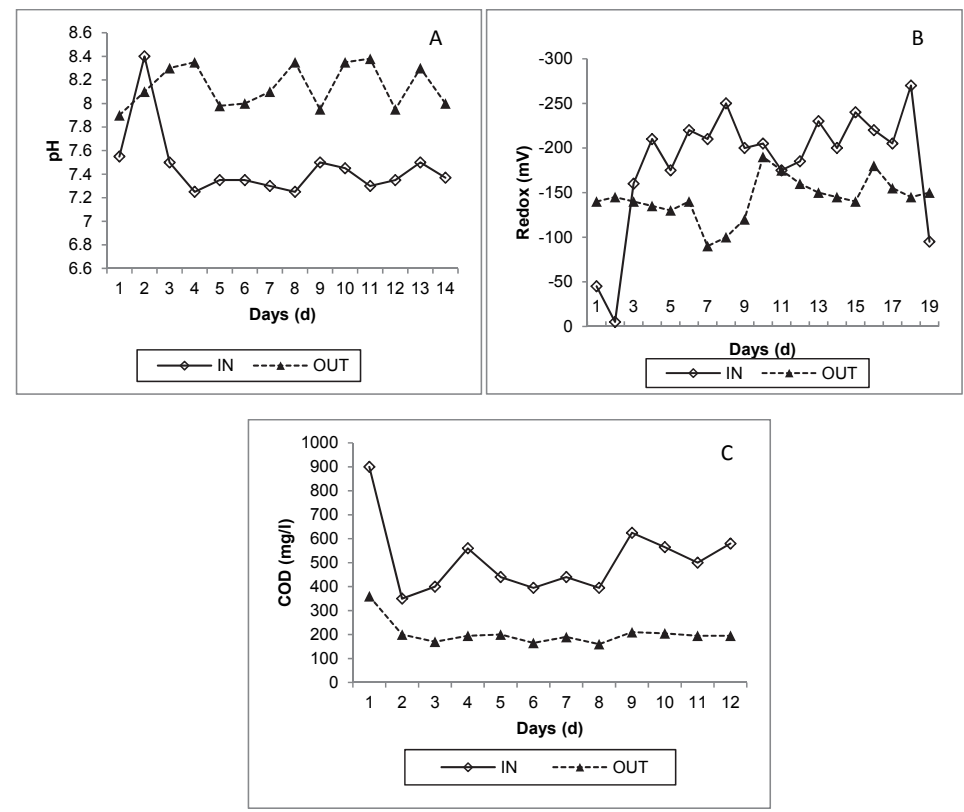

\section{Figure 5}

Influent and effluent $\mathrm{pH}$, Redox potential and COD data measured in the eightchannel Linear Flow Channel Reactor over 18 days at $20^{\circ} \mathrm{C}$ and $2618 \mathrm{l} / \mathrm{m}^{2} / \mathrm{d}$ loading rate. $\mathrm{pH}(\mathrm{A})$, Redox potential (B) and COD (C).

approximately $200 \mathrm{mg} \cdot \ell^{-1}$ during the course of flow through the reactor. This suggests that some reduction of sulphates may have occurred in anaerobic zones within the reactor channels. Since heterotrophic consumption of COD by both sulphatereducing and non-sulphate reducing organisms is likely to have been involved, the component due to sulphate reduction alone could not be quantified in the current study. However, this may need to be taken into account in a more detailed determination 


\begin{tabular}{|c|c|c|c|}
\hline \multicolumn{4}{|c|}{ TABLE 2} \\
\multicolumn{4}{|c|}{$\begin{array}{c}\text { Effect of loading rate on sulphur removal in the } \\
\text { Linear Flow Channel Reactor operated at } \mathbf{2 0}^{\circ} \mathrm{C}\end{array}$} \\
\hline $\begin{array}{c}\text { Loading rate } \\
\left(\ell \cdot \mathrm{m}^{-2} \cdot \text { day }^{-1}\right)\end{array}$ & $\begin{array}{c}\text { Mass } \\
\text { balance } \\
\%\end{array}$ & $\begin{array}{c}\text { Sulphide } \\
\text { removal } \\
\%\end{array}$ & $\begin{array}{c}\text { Sulphur } \\
\text { recovery } \\
\%\end{array}$ \\
\hline 1309 & 94 & 62 & 60 \\
\hline 2618 & 84 & 74 & 43 \\
\hline
\end{tabular}

TABLE 3

Effect of surface area on sulphide removal and sulphur recovery in the Linear Flow Channel Reactor operated at $20^{\circ} \mathrm{C}$

\begin{tabular}{|c|c|c|c|c|}
\hline $\begin{array}{l}\text { Surface area } \\
\qquad\left(\mathrm{m}^{2}\right)\end{array}$ & $\begin{array}{l}\text { Loading rate } \\
\left(\ell \cdot \mathrm{m}^{-2} \cdot \text { day }^{-1}\right)\end{array}$ & $\begin{array}{c}\text { Mass } \\
\text { balance } \\
\%\end{array}$ & $\begin{array}{c}\text { Sulphide } \\
\text { removal } \\
\%\end{array}$ & $\begin{array}{c}\text { Sulphur } \\
\text { recovery } \\
\%\end{array}$ \\
\hline 1.1 & 2618 & 84 & 74 & 43 \\
\hline 2.2 & 2618 & 82 & 88 & 66 \\
\hline
\end{tabular}

of actual sulphide removal achieved in the system.

These results showed that sulphide removal in the LFCR would be expected to be sensitive to seasonal temperature changes. Interestingly, reduced performance would be more pronounced in warmer summer conditions compared to colder winter conditions. This may be controlled for by altering the feed loading rate and/or the reactor surface area, and subsequent studies on the effect of these variables are reported for reactor runs at the $20^{\circ} \mathrm{C}$ optimum operational temperature demonstrated here.

\section{Loading rate}

The effect of loading rate on the performance of the LFCR was evaluated by comparing its operation at $1309 \mathrm{l} \cdot \mathrm{m}^{-2} \cdot \mathrm{day}^{-1}$ and $2618 \mathrm{l} \cdot \mathrm{m}^{-2} \cdot \mathrm{day}^{-1}$ loading rates at $20^{\circ} \mathrm{C}$.

The results of the loading rate studies are shown in Fig. 4 (1 309 l.m $\mathrm{m}^{-2}$.day $\left.{ }^{-1}\right)$ and Fig. 6 (2 618 $\left.\ell \cdot \mathrm{m}^{-2} \cdot \mathrm{day}^{-1}\right)$ and are summarised in Table 2 . In both loading rate studies the removal of sulphide at $62 \%$ for the lower loading rate and $74 \%$ for the higher loading rate was found to be significant $(p<0.05)$ and highly significant $(p<0.0001)$, respectively. The higher the flow rate the better the removal of sulphide observed, with an improvement of around $12 \%$ observed in this study. This difference was also significant $(p<0.05)$.

However, the recovery of sulphur in the form of biofilm harvested was reduced by $17 \%$ at the higher loading rate $(60 \%$ sulphur recovery at the lower loading and $42 \%$ sulphur recovery at the higher loading rate). Indeed, the difference in the sulphur content between the influent and effluent streams was not significant $(p=0.48)$ at the higher loading. This result strengthens the suggestion that the loss of sulphur in each case may be due to fine sulphur particulates that do not settle and are washed out of the system.

In both loading rate studies the difference between influent and effluent thiosulphate and sulphate concentrations was found not to be significant, once again indicating that the sulphide loss was not primarily due to oxidation reactions within the reactor. The reduced likelihood of sulphide stripping as a possible explanation has been noted above although some losses via this route cannot be excluded.

\section{Surface area}

The effect of reactor surface area on the sulphide removal operation in the LFCR was evaluated

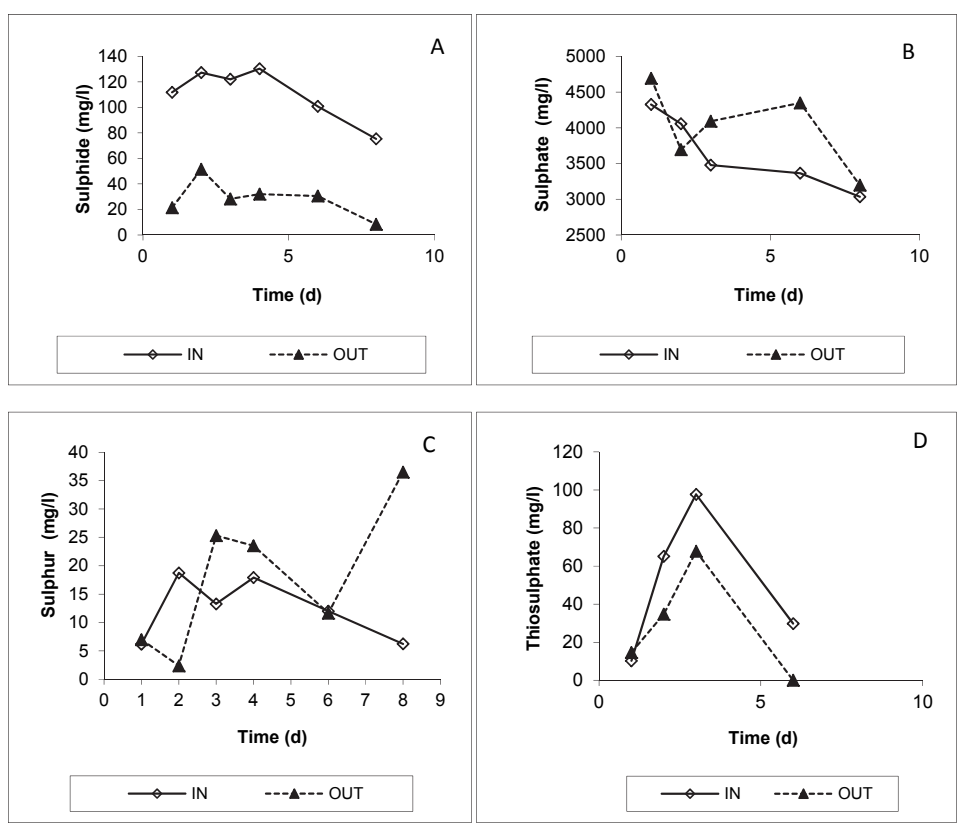

Figure 6

Influent and effluent sulphur species measured in the four-channel Linear Flow channel reactor over 8 days at $20^{\circ} \mathrm{C}$ and $2618 \mathrm{l} / \mathrm{m}^{2} / d$ loading rate. Sulphide (A), sulphate (B), sulphur (C) and thiosulphate (D).
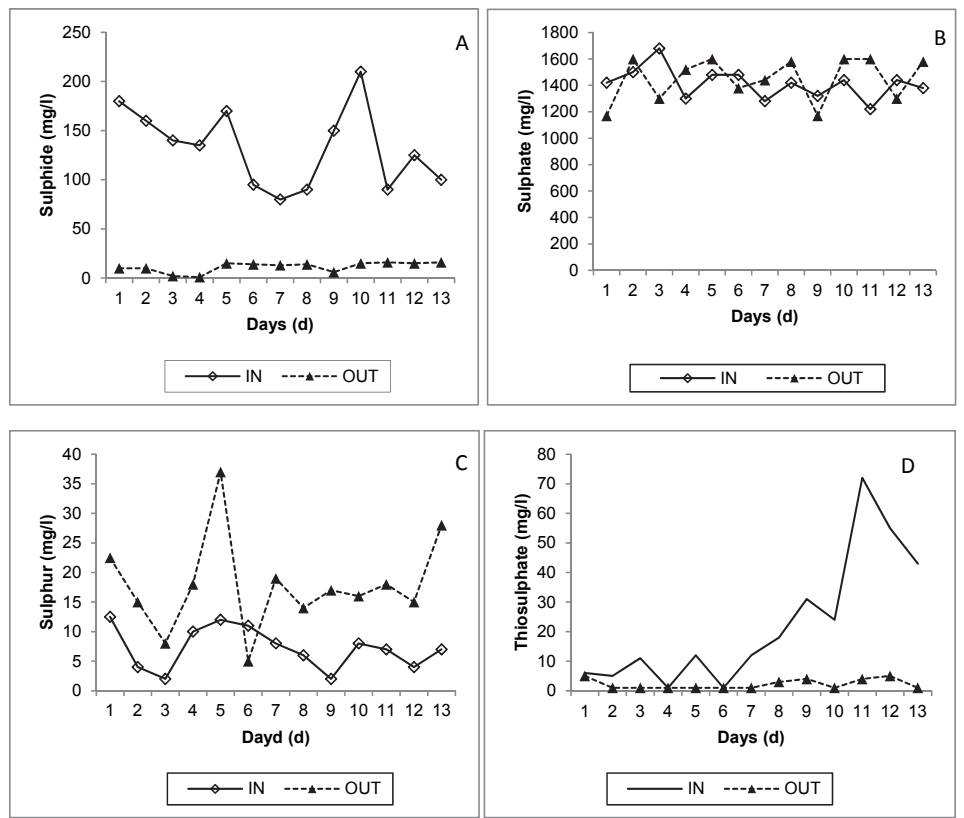

Figure 7

Influent and effluent sulphur species measured in the eight-channel Linear Flow Channel Reactor over 18 days at $20^{\circ} \mathrm{C}$ and $2618 \mathrm{l} / \mathrm{m}^{2} / \mathrm{d}$ loading rate. Sulphide A), sulphate $B)$, sulphur $C$ ) and thiosulphate $D$ ). 
by doubling the 4 -channel reactor area with the addition of another 4 channels. The 8 -channel reactor $\left(2.1 \mathrm{~m}^{2}\right)$ was operated at the $2618 \mathrm{l} \cdot \mathrm{m}^{-2}$. day ${ }^{-1}$ loading rate. Results of this study are shown in Figs. 5 and 7 and summarised in Table 3.

With the increase in surface area, $88 \%$ sulphide removal was measured which was $14 \%$ better than measured in the 4-channel reactor operated at the same loading rate, and $26 \%$ better than in the 4-channel reactor operated at half the loading rate. Sulphur recovery at $66 \%$ showed an improvement of $23 \%$ for the 8 -channel reactor compared to the 4 -channel reactor at the $2618 \mathrm{l} \cdot \mathrm{m}^{-2}$. day ${ }^{-1}$ loading rate, but was more or less comparable to that observed in the reactor operated at the lower loading rate. Once again the difference between influent and effluent thiosulphate and sulphate concentrations was not significant ( $p=0.48$ and $p=0.52$ respectively), indicating that near-complete or complete oxidation of sulphide does not provide an explanation for the major fraction of unaccounted sulphur in the system.

\section{CONCLUSIONS}

The results of the study reported here have shown the following: The LFCR offers a relatively simple system for sulphide removal following sulphate reduction in passive treatment operations such as those managed in DPBR units handling AMD flows. Sulphide removal of up to $88 \%$ may be achieved in the system and with sulphur recovery of around $60 \%$ in the form of polysulphide and $\mathrm{S}_{\mathrm{o}}$ granules.

The process is temperature sensitive and process design will need to take into account losses to be expected in both hot and cold climatic conditions.

The process is responsive to both loading rate and reactor surface area but, within the context of this study, it was observed that higher loading rates and larger reactor surface areas were both associated with higher sulphide removal in the treatment stream.

Total S removal in the AMD feed stream in the LFCR system will require control of the fine particulate sulphur fraction generated in the process and improvement of the separation function requires further study.

While the initial potential of the process has been demonstrated, further refinement of kinetic data is required to improve design inputs required for effective scale-up of the process. Initial studies in this regard have been reported by Van Hille et al. (2011).

Potential has been demonstrated in this study for the scale-up evaluation of the system for use in field-scale passive treatment operations. Such studies have commenced and preliminary results of findings have been reported by Mack et al. (2009).

\section{ACKNOWLEGEMENTS}

The authors would like to thank Rhodes University, the Environmental Biotechnology Research Unit and the Water Research Commission for funding Project K5/1454 and for permission to use data from WRC Report No. TT 411/09.

\section{REFERENCES}

APHA (AMERICAN PUBLIC HEALTH ASSOCIATION) (2005) Standard Methods for the Examination of Water and Wastewater $\left(21^{\text {st }}\right.$ edn.) American Public Health Association, Washington, DC.

BOWKER ML (2002) The biology and molecular ecology of floating sulphur biofilms. MSc thesis, Rhodes University, Grahamstown.

COETSER SE, HEATH R, MOLWANTWA JB, ROSE PD and PULLES W (2005) Implementation of the degrading packed bed reactor technology and verification of the long-term performance of passive treatment plants at Vryheid Coronation Colliery. WRC Report No. 1348/1/05, Water Research Commission, Pretoria.

DUNN KM (1998) The biotechnology of high rate algal ponding systems in the treatment of saline tannery wastewaters. PhD thesis, Rhodes University, Grahamstown.

FIELD S (2003). The Earth's open wounds: Abandoned and orphaned mines. Environ. Health Perspect. 111 a154-a161.

GILFILLAN J (2000) The structure and microbiology of floating sulphur oxidizing biofilms. MSc thesis, Rhodes University, Grahamstown.

MACK CL, RAJA SA, PULLES WB, MUHLBAUER RC and HEATH RA (2009) Application of the linear flow channel reactor (LFCR) for the removal of sulphide from semi-treated acid mine drainage (AMD). Abstracts of the International Mine Water Conference, 19-23 October 2009, Pretoria.

McCARTHY TS (2011) The impact of acid mine drainage in South Africa: commentary. S. Afr. J. Sci. 107 (5\&6) 1-7.

MOCKEL HJ (1984) Retention of sulphur and sulphur organics in reversed-phase liquid chromatography. J. Chromatogr. 317 589-614.

MOLWANTWA JB (2008) Floating sulphur biofilms: Structure function and biotechnology. PhD thesis, Rhodes University, Grahamstown.

MOLWANTWA JB, COETSER SE, HEATH R and ROSE PD (2007). Development of the floating sulphur biofilm reactor for sulphide oxidation in biological water treatment systems. Water $S A 30$ (5) 655-657.

MOLWANTWA JB, BOWKER M, GILFILLAN J, REIN N, DORRINGTON R, HART OO and ROSE PD (2009) Investigation and development of the biotechnology of the floating sulphur biofilm in the beneficiation and treatment of wastewater. WRC Report No. TT 411/09. Water Research Commission, Pretoria.

REIN NB (2002) Biological sulphide oxidation in heterotrophic environments. MSc thesis, Rhodes University, Grahamstown.

ROSE PD (2005) Meeting the sustainability challenge: trends and developments in biological treatment of mine drainage in South Africa. $9^{\text {th }}$ International Mine Water Congress, 5-7 September 2005, Oviedo, Spain,.

ROSE PD, MAART BA, DUNN KM, ROWSWELL RA and BRITZ P (1996) High rate oxidation ponding for the treatment of tannery effluents. Water Sci. Technol. 33 219-227.

ROSE PD, DUNN KM, MAART BA and SHIPIN O (2002) Integrated ponding systems and the treatment of saline wastewaters. WRC Report No. TT 188/02. Water Research Commission, Pretoria.

STEUDEL R (1996) Mechanism for the formation of elemental sulfur from aqueous sulfide in chemical and microbiological desulfurization processes. Ind. Eng. Chem. Res. 35 1417-1423.

VAN HILLE RP, VAN WYK N, MOTLELENG L and MOORUTH N (2011) Lessons in passive treatment: Towards efficient operation of a sulphate reduction - sulphide oxidation system. Abstracts of the International Mine Water Conference, 4-11 September 2011, Aachen, Germany. 